\title{
KOMUNIKASI SOSIAL SISWA DI SMP NEGERI 34 PADANG
}

\author{
Anggia Nurmila, Nurman, Maria Montessori \\ Program Studi Pendidikan Pancasila dan Kewarganegaraan \\ FIS Universitas Negeri Padang \\ E-mail : anggianurmila95@gmail.com
}

\begin{abstract}
This study aims to obtain an overview of the forms of social communication of students in Padang 34 Public Middle School and the school's efforts to improve good student social communication in Padang Public Middle School 34. This study uses qualitative assessment. 17 people were selected by purposive sampling in 34 Padang Public Middle School. Data was collected by observation, interview and documentation. To ensure data validation used source triangulation, then the analyzed data refers to the stages of Miles and Huberman's data analysis with stages, namely: data reduction, data presentation, and conclusion drawing. The results of the study showed that students 'social communication in Padang State Middle School 34, which included forms of student social communication and school efforts in improving students' social communication in the School. The forms of social communication of students in SMP N 34 Padang are: social communication in learning, social communication and gang (group), and social communication in school hygiene activities. As well as efforts made by schools in improving students' social communication with the existence of coaching activities for students and class parenting activities. Fostering students and parenting classes for students by creating conditions or making students aware of the behavior, character of students, and how students learn. this is a way to overcome problems with students' social communication.
\end{abstract}

Keywords: communication, social, students.

Abstrak

Penelitian ini bertujuan untuk memperoleh gambaran tentang bentuk komunikasi sosial siswa di SMP Negeri 34 Padang dan upaya sekolah dalam meningkatkan komunikasi sosial siswa yang baik di SMP Negeri 34 Padang.Penelitian ini menggunakan pendektan kualitatif. 17 orang yang dipilih dengan purposive sampling yang berda di SMP Negeri 34 Padang .Data dikumpulkan dengan cara observasi, wawancara dan dokumentasi. Untuk memastikan validasi data digunakan trianggulasi sumber selanjutnya data dianalisis mengacu kepada tahapan analisis data Miles dan Huberman dengan tahapan yaitu: reduksi data, penyajian data, dan penarikan kesimpulan.

Hasil penelitian menunjukan bahwa komunikasi sosial siswa di SMP Negeri 34 Padang, yang mencangkup bentuk komunikasi sosial 
siswa dan upaya sekolah dalam meningkatkan komunikasi sosial siswa di Sekolah. Bentuk-bentuk komunikasi sosial siswa di SMP N 34 Padang yaitu : komunikasi sosial dalam pembelajaran, komunikasi sosial dalam geng (kelompok), dan komunikasi sosial dalam kebersihan lingkungan kelas. Serta upaya yang di lakukan oleh sekolah dalam meningkatkan komunikasi sosial siswa dengan adanya kegiatan pembinaan bagi siswa dan kegiatan parenting kelas. Pembinaan siswa dan parenting kelas yang dilakukan kepada siswa dengan menciptakan kondisi atau membuat siswa sadar akan tingkah laku, karakter siswa, dan cara belajar siswa. ini merupakan cara untuk mengatasi permasalahan terhadap komunikasi sosial siswa.

Kata Kunci : komunikasi, sosial, siswa.

\section{Pendahuluan}

Sekolah merupakan lembaga pendidikan yang diharapkan dapat memberikan kontribusinya dalam membina komunikasi sosial. Hasil komunikasi sosial di sekolah mencakup kemampuan siswa dalam berkomunikasi yang baik di lingkungan sekolah maupun di masyarakat. Dalam hal ini sekolah diharapkan mampu mencapai suatu sasaran yang dapat dilihat dari hasil komunikasi sosial siswa nantinya. Dampak komunikasi sosial membawa hubungan yang baik antara individu dengan lingkungannya. Demikian pula, pada aspek sikap siswa diharapkan memiliki perilaku dan karakter yang menjadi modal dalam melakukan hubungan dan tindakan sosial. Hasil komunikasi sosial ini merupakan suatu kegiatan pendidikan yang merupakan proses perubahan perilaku yang dituntun secara alamiah dan spontan (Sumaatmadja, 2002:41). Salah satu indikasi bahwa manusia sebagai makhluk sosial adalah perilaku komunikasi antar manusia. Manusia tidak dapat hidup sendiri, pasti membutuhkan orang lain. Dari lahir sampai mati, cenderung memerlukan bantuan dari orang lain ( tidak terbatas pada keluarga, saudara dan teman). Kecendrungan ini dapat dilihat dalam kehidupan sehari-hari yang menunjukan fakta bahwa semua kegiatan yang dilakukan manusia selalu berhubungan dengan orang lain ( Suranto A W, 2011:1).

Ada banyak pilihan dalam kehidupan seorang siswa pada umumnya. Dimana pada fase ini disebut sebagai fase peralihan dari anak-anak menjadi siswa yang masih remaja cenderung "mencobacoba" setiap apa yang dihadapi di lingkungannya sehingga terkadang orang tua menjadi khawatir terhadap perkembangan anaknya. Sehingga tidak sedikit orang tua rela untuk membayar mahal demi untuk menyekolahkan anaknya di sekolah-sekolah yang bermutu baik. Tetapi, terkadang hal yang seperti ini membuat seorang anak merasa 
terbebani karena merasa tertekan atas pilihan orang tua dan memaksakan kehendaknya untuk mengikuti kemauan orang tua. Sehingga tidak sedikit sekolah- sekolah yang dianggap mempunyai mutu yang baik oleh masyarakat menjadi sebuah pelarian bagi mereka yang mampu untuk menyekolahkan anaknya disekolah tersebut.

Berdasarkan observasi awal pada tanggal 30 Juli 2018 di SMP N 34 Padang. Hasil observasi awal peneliti dapatkan dengan cara mengamati siswa dalam berkomunikasi sosial di lingkungan sekolah, selanjutnya mewawancarai 7 orang peserta didik yang bernama andika wahyu ramadhan, Reyhan azhar ramadhan, Rhafli, Yoga andika saputra, Anggito abimanyu, Fadly prahmandana, Rio anugrah dan salah sesorang guru yang bernama Ibu Everianti, S.Pd, yang menyatakan bahwa:

"Tidak menghormati guru yang sedang melakukan proses pembelajaran di kelas, berkata kotor di dalam kelas, kurang sopan santun siswa dalam berbicara, dan adanya siswa yang mengalami kendala dalam berkomunikasi sosial, ini terlihat dari cara siswa dalam berjomunikasi sosial di lingkungan sekolah."

Selain itu pada saat melakukan pengamatan dilapangan peneliti juga menemukangejala-gejala permasalahan yaitu melihat secara lansung siswa dalam berkomunikasi sosial antara teman sejawat serta komunikasi sosial dengan guru. Namun, kondisi yang terjadi di sekolah, tidak sepenuhnya terjadi seperti yang diharapkan yaitu mencangkup kemampuan komunikasi sosial siswa dalam berkomunikasi yang baik yang diharapkan mampu mencapai sasaran yang dapat di lihat dari hasil komunikasi sosial siswa nantinya, baik di lingkungan sekolah maupun di masyarakat. Sebaliknya yang terjadi adalah kurang optimal nya harapan dari sekolah terhadap komunikasi sosial siswa.. Kondisi-kondisi yang terjadi di sekolah tersebut adalah kelemahan dalam komunikasi sosial yang segera perlu di atasi. Salah satu cara untuk mengatasi hal tersebut adalah dengan meningkatkan komunikasi yang baik antara sesama teman sejawat baik di dalam lingkungan sekolah maupun di luar lingkungan sekolah.

Menelaah harapan dan kenyataan pada latar belakang, peneliti menyimpulkan bahwa sangat perlu dilakukan penelitian untuk menganalisis kemampuan komunikasi sosial siswa melalui komunikasi sosial. Serta kemampuan berkomunikasi sosial ini merupakan modal bagi siswa dalam mengembangkan pola keteraturan dan dinamika kehidupan sosial dimasyarakat. Berdasarkan penjelasan maka dari itu peneliti merumuskan penelitian dengan judul: "Komunikasi Sosial Siswa Di SMP Negeri 34 Padang." 


\section{Metode Penelitian}

Penelitian ini menggunakan pendekatan kualitatif dengan deskriptif kualitatif. Imforman dalam penelitian ini 17 orang yang dipilih dengan teknik purposive sampling. maka yang mejadi imforman dalam penelitian ini direncanakan yaitu Kepala sekolah, wakil kurikulum, wakil kesiswaan, guru-guru, dan beberapa orang Siswa kelas VII, VIII, IX, yang ada di SMP N 34 Padang. Data dikumpulkan dengan observasi, wawancara mendalam dan dokumentasi. Untuk memastikan validitas data digunakan triangulasi serta untuk analisis data yaitu reduksi data, penyajian data, penarikan kesimpulan dan verifikasi.

\section{Hasil dan Pembahasan}

Dalam penelitian ini ditemukan fakta di lapangan yaitu sebagai berikut :

\section{Bentuk-bentuk Komunikasi Sosial Siswa Di SMP Negeri 34 Padang.} 1) Komunikasi Sosial Dalam Pembelajaran

Dalam pembelajaran para siswa berkomunikasi menggunakan bahasa-bahasa dengan simbol-simbol tertentu baik dengan teman-temannya maupun bersama gurunya. Dalam observasi yang peneliti lakukan terlihat bahwa komunikasi sosial yang terjadi di sekolah dalam pembelajaran di kelas, terbukti di kelas VII.1 yang terdiri dari 31 orang siswa, masing-masing siswa saling beradu argument dan berdiskusi dengan teman-temanya tentang topik pembahasan pada saaat pembelajaran berlansung.

Misalnya ketua kelas yang bernama Muhammad Fajar menanyakan kepada teman-temannya tentang soal-soal yang diberikan oleh guru mata pelajaran, apakah sudah selesai di kerjakan oleh semua siswa atau belum dengan menggunakan bahasa baku (minang), dan teman-temannya mengerti dengan apa yang dikatakan oleh Muhammad Fajar tersebut. Ketika hal tersebut ditanyakan kepada Muhammad Fajar, mengapa dia menggunakan bahsa baku (minang) fajar menjawab bahwa dia menggunakan bahasa baku (minang) tersebut karena teman-temannya juga sama dengan dia, otomatis teman-temannya mengerti dengan dengan apa yang di ucapkan Muhammad Fajar tersebut.

Meski demikian siswa dengan gurunya menggunakan bahasa Indonesia, tidak semua siswa juga menggunakan bahasa Indonesia ketika bertanya kepada gurunya. Namun ada beberapa siswa bertanya kepada guru mata pelajaran tersebu menggunakan bahasa baku (minang). Serta berbagai macam kelakuan siswa di dalam kelas (seperti malas-malasan, tidur di kelas serta mengganggu teman lainnya). 
Berdasarkan hasil wawancara, observasi dan dokumentasi yang dijabarkan diatas maka dapat disimpulkan bahwa komunikasi sosial dalam pembelajaran yang di lakukan siswa sudah baik namun masih belum optimal, masih adanya masalahmasalah yang dialami dalam belajar, terlihat seperti tidak saling menghargai antara siswa dengan siswa serta siswa dengan guru sehingga akan menimbulkan perilaku-perilaku yang tidak baik. Tanpa adanya kesadaran akan penting hidup bersama-sama untuk mencapai tujuan yang bersama, masih adanya sifat individual yang hanya mementingkan diri sendiri dan tidak mementingkan temantemanya yang lain.

\section{2) Komunikasi Sosial Dalam Geng (Kelompok)}

Berdasarkan pengamatan yang peneliti lakukan saat penelitian terlihat bahwa adanya geng-geng (kelompok) tertentu baik di dalam pembelajaran dikelas maupun di luar kelas yang dibentuk oleh siswa itu sendiri. Ternyata komunikasi yang mereka lakukan begitu intens, satu sama lain saling berhubungan atau membutuhkan. Kelompok-kelompok yang mereka buat bersifat formal dan informal.

Di dalam geng-geng (kelompok) yang mereka buat memerlukan adanya bimbingan serta arahan dari guru agar siswasiswa yang membentuk geng-geng tidak mengarah kepada hal-hal yang tidak baik dan menjalin komunikasi yang baik di antara mereka. Ketika jam istirahat berlansung maka akan terlihat siswasiswa dengan geng-geng (kelompok) tertentu keluar kelas untuk berbelanja di kantin sekolah atau jajanan-jajanan yang ada di luar sekolah. Mereka saling bercerita didalam geng-geng tersebut, baik cerita tentang pembelajaran di kelas maupun cerita-cerita tentang sosmes (sosial media) yang mereka punya. Di dalam geng-geng (kelompok) tersebut akan terlihat dengan jelas mereka memisahmisahkan diri diantara geng-geng tertentu.

Hal tersebut terjalin dengan sendirinya berdasarkan berbagai macam latar belakang, baik bidang ekonomi, siswa yang juara dan rajin belajar, serta berdasarkan siswa-siswa yang suka bercanda sesama mereka, namun ada beberapa siswa yang tidak mau bergabung dengan geng-geng (kelompok) yang dibuat oleh mereka dengan berbagai alasan yang mereka nyatakan yaitu tidak sesuai dengan criteria mereka, di dalam geng saling menghujat satu sama lainnya, berdasarkan dari kalangan ekonomi yang kurang, tidak rajin dalam belajar, dan lain sebagainya. 
Berdasarkan hasil wawancara, observasi dan dokumentasi yang dijabarkan sebelumnya maka dapat disimpulkan bahwa komunikasi sosial yang terjadi dalam anggota geng-geng (kelompok) yang terjalin di antara para siswa sudah baik namun belum optimal, masih terdapat dampak negatif dari geng-geng yang ada di kalangan siswa. baik itu yang menimbulkan perilaku yang tidak baik maupun bahasa-bahasa yang tidak baik yang di gunakan.

3) Komunikasi Sosial Dalam Kegiatan Kebersihan Lingkungan Sekolah

Berdasarkan pengamatan yang peneliti lakukan pada saat penlitian saat kegiatan kebersihan lingkungan sekolah dilaksanakan, baik siswa maupun guru ikut berpartisipasi di dalam kegiatan ini. Terbukti dengan lingkungan sekolah yang di berikan nama sekolah Adiwiyata sekota padang, lingkungan sekolah yang masih astri dan bersih membuat sekolah ini di nobatkan sebagai sekolah adiwiyata.

Terlihat bermacam kelas-kelas yang berbeda-beda di sekolah tersebut, masing-masing kelas akan berlomba-lomba untuk memenangkan lomba kejuaraan kelas yang diselenggarakan oleh sekolah tersebut. Terlihat di depan kelas VIII.3 siswa sedang melaksanakan kegiatan kebersihan untuk mempercantik kelas mereka masing-masing. Dari banyak siswa yang ikut berpartisipasi di dalam kegiatan tersebut namun ada beberapa siswa yang masih acuh tak acuh dengan kegiatan, mereka hanya menlihat-lihat saja tanpa ikut serta dalam kegiatan tersebut.

Selain para siswa guru-guru juga ikut berpartisipasi, mereka membuat taman-taman bunga dan taman-taman jenis tumbuhan obat-obatan yang berada di belakang Sekolah SMP N 34 Padang. Dengan berbagai kegiatan tersebut akan meningkatkan hubungan yang baik di antara para siswa maupun dengan gurunya. Tidak dapat dipungkiri bahwa kegiatan ini sangat berdampak positif terhadap kehidupan siswa kedepanya.

Berdasarkan hasil observasi, wawancara dan dokumentasi yang dijabarkan sebelumnya maka dapat disimpulkan bahwa kegiatan kebersihan lingkungan kelas baik di kelas-kelas maupun di lingkungan sekolah sudah terlaksana dengan baik namun masih belum optimal, masih ada terdapat kekurangan-kekurangan dalam kegiatan ini. Meskipun masih ada beberapa siswa yang tidak mau ikut serta dalam kegiatan ini, namun kegiatan ini tetap terlaksana dengan baik. 


\section{Upaya Sekolah Dalam Meningkatkan Komunikasi Sosial Siswa yang Baik di SMP Negeri 34 Padang.}

Berbagai upaya di lakukan sekolah dalam meningkatkan komunikasi sosial siswa. Berdasarkan hasil temuan yang peneliti temukan di lapangan pada saat penelitian terlihat bahwa adanya berbagai macam upaya yang dilakukan sekolah demi terciptanya komunikasi sosial siswa dengan baik. Terlihat para siswa mengikuti kegiatan-kegiatan untuk meningkatkan komunikasi sosial itu sendiri. Ini terbukti dalam beberapa kegiatan yaitu pembinaaan siswa dan kegiatan parenting kelas.

1) Pembinaan Siswa

Pembinaan siswa adalah pemberian layanan kepada siswa di suatu lembaga pendidikan. Pembinaan kepada siswa dilakukan baik didalam maupun di luar jam belajarnya di kelas. Pembinaan kepada siswa dilakukan dengan menciptakan kondisi atau membuat siswa sadar akan tugas-tugas belajarnya. Beberapa hal dilakukan saat pembinaan adalah : tingkah laku siswa, karakter siswa, cara belajar siswa, dan nilai-nilai siswa.

Berdasarkan hasil temuan yang peneliti temukan di lapangan, terbukti bahwa kegiatan-kegiatan pembinaan yang dilakukan sekolah untuk menumbuhkan kesadaran siswa akan pentingnya komunikasi sosial bagi kehidupan mereka pada saat nantinya. Dengan kegiatan-kegiatan tersebut di atas terlihat sangat jelas sekali pengaruh yang baik bagi siswa-siswa yang ada di SMP N 34 Padang.

2) Parenting Kelas

Parenting kelas adalah upaya yang dilaksanakan oleh waliwali kelas dengan siswa maupun pihak keluarga dengan memamfaatkan sumber-sumber yang tersedia dalam keluarga dan lingkungan dalam bentuk kegiatan belajar secara mandiri.

Berdasarkan hasil temuan yang peneliti temukan dilapangan , terbuktu bahwa kegiatan parenting kelas yang dilakukan sekolah sangat menunjang sekali terhadap kemajuan perilaku dan nilainilai siswa kea rah yang lebih baik, namun disisi lain bahwasannya tidak semua orang tua yang ikut berpartisipasi dalam kegiatan ini, karena ada sebagian orang tua siswa yang tidak terlalu memperdulikan lagi anaknya dikarenakan kesibukan oarang tua atau kekesalan orang tua terhadap perilaku anaknya yang terlalu berlebihan. 


\section{Kesimpulan}

Berdasarkan hasil penelitian dan pembahasan yang dilakukan di SMP Negeri 34 Padang. yaitu sebagai berikut:

1. Bentuk komunikasi sosial siswa yang terjadi di sekolah tersebut yaitu: komunikasi sosial dalam pembelajaran, komunikasi sosial dalam geng (kelompok), dan komunikasi sosial dalam kegiatan kebersihan lingkungan sekolah sudah baik namun belum optimal karena latar belakang budaya siswa itu sendiri, berbagai cara sudah dilakukan pihak sekolah untuk membina agar komunikasi sosial siswa itu baik nantinya. karena pendidikan itu bukan hanya beranjak dari sekolah saja, awalnya beranjak dari kelurga yang kebanyakan berlatarbelakang orang pantai (pasir) dan tinggal dilingkungan pasar, mungkin apa yang mereka lakukan di rumah terbawa-bawa kesekolah, ini sangat berpengaruh sekali terhadap komunikasi sosial siswa tersebut.

2. Upaya yang dilakukan sekolah dalam meningkatkan komunikasi sosial siswa di SMP N 34 Padang agar berjalan dengan baik dan efektif yaitu : kegiatan pembinaan dan parenting kelas. Kegiatan pembinaan dan parenting kelas yang dilakukan sekolah merupakan salah satu upaya untuk meningkatkan komunikasi sosial siswa itu sendiri.

\section{DAFTAR PUSTAKA}

Urman, Irvan. 2013. Kepribadian, Komunikasi, Kelompok Teman Sebaya, Iklim Sekolah dan Perilaku Bullying. Jurnal Mahasiswa.10(1): 50-60.

Hardianto. Komunikasi Yang Efektif Dalam Pendidikan Islam. Jurnal Dosen STAIN Tuanku Tambusai Pasir Pengaraian. 4(2). 51-66.

Ataymini, Rahmah. 2014. Upaya Membangun Komunikasi Yang Efektif Antar Pribadi. Skripsi: Universitas Islam Negeri Yogyakarta.

Amalia, Ida Risky. 2014. Komunikasi Interpersonal siswa. Skripsi:Universitas Pembangunan Nasional "Veteran" Jawa Timur. 